\title{
The Use of Digital Communication to Build Care and Relationships into the Post-Secondary Classroom: A Self- Analysis of Discourse
}

\author{
Jennifer Rider \\ Department of Teacher Education, Fort Lewis College, Durango, CO, USA \\ Email: jrider@fortlewis.edu
}

\begin{abstract}
Relationships are central to teaching and learning in higher education contexts. Positive relationships between faculty and students can be built on ethics of care (Noddings, 2005). By increasing rhetorical awareness in online communication with students, faculty can reflect on how discourse forms may mask forms of care toward students (Blommaert, 2005). This study uses a selfanalysis of discourse to focus on how higher-education faculty uses technological tools to incorporate ethics of care into their relationships with students. In exploring the question "What themes of care can be present in digital discourse?" fourteen themes of care emerged from the data analysis. The findings offer considerations for discourse use and five tenets for building care into online communication with students.
\end{abstract}

Keywords: Ethics of care, online discourse, faculty-student relationships, higher education, online learning technologies

\section{Introduction}

In her TED Talks "Every kid needs a champion," Rita Pierson (2013) speaks about the importance of human connection: relationships. She states that "kids don't learn from people they don't like." Having spent years as a public school teacher as well as an instructor in higher education, I can confidently say that relationships are an integral part of teaching and learning. If you have ever spent time in a classroom of any type, you understand and have experienced the power of building relationships with students and how that impacts their motivation, social-emotional wellbeing, and their academic progress. James Comer (1995) believes that no significant learning can occur without a significant relationship. While we often have some students who are intrinsically motivated to perform well in school whether or not they like you as the teacher, kids who struggle with school are more likely to overcome particular challenges with the teacher's care and support.

\section{Review of the Literature}

\subsection{An Ethic of Care}

According to Noddings (2005), care is much more than a warm fuzzy feeling that students get when a teacher is kind or likeable. A caring teacher fosters student knowledge, supports the skills that are necessary to contribute positively as a human being, and involves a mutual relationship around learning. When caring is embedded in democratic relationships with students, teachers become part of the process with students to co-construct meanings and intended learning occurs through shared understanding (Oakes, Anderson, Lipton, \& Stillman, 2012). A teacher's role extends far beyond offering knowledge to students, but rather, it includes facilitating growth, developing citizenship, caring for students as human beings and individuals, and modeling positive relationships. "Caring encompasses the moral and cultural values of how people relate to others" (Oakes et al., 2012, p. 238), thus should be an essential part of every student-teacher relationship. Hence, teaching becomes much more than just delivering content to learners.

Instead of focusing on standardized test scores and student achievement, students should be "given 
opportunities to learn how to care for themselves, for other human beings, for the natural and humanmade worlds and for the world of ideas" (Noddings, 2005, p. xiii). Learning to care, Nodding explains, is what defines genuine education. While this may be a contentious topic among educators, we cannot deny that students (and people in broader contexts) learn better from those who they know, respect, and who care about them. We must acknowledge that the definition of care varies greatly among parents, families, communities, policy makers, teachers, and schools. Caring for students encompasses our pretexts regarding what people need for their emotional, physical and academic well-being. They are inseparable, so we must be cautious about how we approach the context of care in educational spaces. Noddings (2005) defines care as responding sensitively and positively to "expressed needs that are morally and educationally defensible" (p. xvii). The ethic of care espouses a commitment to responsiveness, listening to our students, and trying to address their needs (Noddings, 2005). Therefore, caring means that when we interact with students we consider their needs, respond positively, and lay aside all forms of power, judgment, and criticism. Caring means that we show empathy and support for our students.

The central idea in an ethic of care is that "the living other is more important than any theory" (Noddings, 2005, p. xix). This may be challenging for faculty at higher education institutions who are entrenched in academia, theory, and policy. We are experts in our fields and therefore have a strict notion of the way things work. When students stray from the learning or dispositional expectations, we may be quick to judge or make assumptions. This is extremely present in online communications when no body language or tone of voice is present. Because it is possible to leave out many forms of care in online communication, we must be aware of how we model caring interactions and relate to students who express needs or challenges. Noddings (2005) argues that care can only build strong teacher-student relationships when both participants (the carer and the cared-for) reciprocate the actions. If an instructor demonstrates care in the same way to each student without taking into consideration the individual student and his/her identity, care may not be received as authentic and genuine. Caring for a human subject also encompasses the desire to help a person in need. Motivational displacement may occur in situations where we set aside our own motives in order to make the needs of others a higher priority in the moment. In this case, demonstrating the ethic of care is the act of helping others or having the intention to help others with their needs.

Ethics of care can be found in both interactions and spatial contexts. Care through interactions involves developing a common discourse that uses empathy, respect, and an asset-perspective. Care within spatial contexts may include student-centered learning, respectful curriculum, and a safe and inclusive environment for students to learn. "To teach is to create a space in which the community of truth is practiced" (Palmer, 1997, p. 4). Palmer challenges us to create a deep and personal learning community centered around the academic content, offering a sense of connectedness to learning. He claims that we can achieve this by bringing in a third thing, the subject, which allows for students and teachers to disconnect from their own power, and engage in new content that sparks curiosity and meaningful learning. He questions if community can truly happen when there are divisions of power, specifically with the authority of the teacher and their role as evaluators. If you have ever experimented with establishing a truly democratic learning space with shared ownership between the teacher and the students, you know how challenging this can be when the teacher holds authoritative powers that are impossible to absolve (such as assigning grades). However, I have never witnessed an educator speaking about extreme challenges regarding caring for students and building positive relationships. We are all capable of making human connections, and these are a crucial element of the classroom environment.

\subsection{Care in Higher Education}

Noddings (1995) believes that the public school curriculum deserves to be reorganized, integrating themes of care (within the school as well as on a community and global level), and I argue that themes of care also need to be present in higher education classrooms and discourse. Given all of the grave problems that are happening within our educational system, more emphasis on rigorous curriculum may not be the answer. Students are unlikely to achieve success if they do not believe that they are cared for, or incapable of caring for others (Noddings, 1995). While care is a word that most people use frequently in and out of education, Noddings (1995) clarifies and defines the notion of care from the institutional level down to the individual level. We can manifest care in the curriculum we choose, the level of 
investment in units that we plan and teach, and themes that we emphasize in our teaching, such as poverty, racism, or sexism, as examples. Noddings' work gives us a strong theoretical foundation for how to create an environment of care and its impact on students' social-emotional and academic well-being. The literature begins to thin when we search for strong empirical evidence to support how to incorporate care into the student-teacher relationship, especially within higher education contexts. Specific and tangible methods, strategies and tenets must be available for teachers to improve the way in which they communicate with students in order to foster a sense of caring for the students' academic and emotional wellbeing. With technology being a common tool for discourse by students and teachers of all ages and technological proficiency levels, it is imperative that we begin to explore how care is infused into the digital discourse between teachers and students.

Themes of care can be explored through the processes of inquiry, dialogue, reflection, and response, and should be an integral part of all courses and disciplines (Noddings, 2005). The act of caring has multiple facets in education, including curriculum design, pedagogical practices, and assessment techniques. This paper focuses on themes of care present through dialogue and communication with students in higher education. Through every interaction with students, we must be cognizant of the assumption that "spaces are contested and actively constructed through interactions" (Wood \& Lemley, 2015 , p. 4). By uncovering the underlying ideologies that work to maintain power structures in society, we may be able to dismantle the "teacher power" that often intimidates and controls students' actions. True dialogue requires the dialoguers to engage in critical thinking, and to form a solidarity that is absent of any dichotomy between them. Without communication there can be no true education" (Freire, 1970, p. 93). I focus my research and themes of caring in the form of digital communication and demonstrating care through what has become a very common way to communicate: e-mail.

\subsection{Care within Culturally Responsive Teaching}

As educators, we all make assumptions based on what we perceive to be true, and we are driven by our biases and pretexts that may go disguised until a deep and authentic reflection takes place to unmask those assumptions. Due to our assumptions, we may fail to recognize the cultural capital that children bring to the classroom, and we fall into the perpetuation of pedagogy of poverty by teaching to a set of values that are irrelevant to the child (Valdes, 1996). Valdes's (1996) work is representative of what we should be doing as teachers: learning about our students and their histories that contribute to who they are as a learner. We often make assumptions or generalizations that simply are not applicable to many students, yet affect how we go about teaching. Curricular themes of care can incorporate students' cultural literacy, help interrelate multiple disciplines, present existential questions, build personal relationships, and execute a "continuous search for competence" (Noddings, 1995, p. 2).

The true aim in education should be to "produce people who are morally good, intellectually competent, socially sensitive, spiritually inquisitive, and committed to living full and satisfying lives" (Noddings, 2014, p. 16). Good teachers respond to the diverse needs of their students on a daily basis, and strive to teach beyond the standards. Responsiveness is a key element to incorporating democratic and caring ideals in education, and schools and teachers should reflect on and improve ways in which they are responsive to the needs of students and families (Noddings, 2005). "Caring teachers listen and respond differentially to their students" (Noddings, 2005, p. 19). Learning new "cultural codes" of the diverse student body transforms the classroom (hooks, 1994). These cultural norms can shape the discourses that we have with students both in the classroom as well as through online contexts. Using the ethic of care in our personal and academic discourse with students helps to differentiate learning for students depending on their unique needs.

\subsection{Care in Literacy, Language and Discourse}

Literacy and language encompass a variable level of inquiry in meaning making. Goodman (1996) states that as you read, "you have the sense of 'seeing through' the print directly to meaning, because your perception of print, like your perception of speech, is controlled by your need to make sense" (p. 13). Recipients of written forms of discourse perceive meanings based on their own assumptions, even if tone is not evident in the text. If a student is always assuming that she did not do an assignment correctly, when a teacher emails to request a meeting to talk about the assignment, the student's assumptions will 
be respective of her pretexts. Therefore, digital discourse becomes a delicate practice that requires reflective and empathetic processes.

In his recent New York Times article, "When You're in Charge, Your Whisper May Feel Like a Shout," Galinsky (2015) speaks about the power of words and tone of voice. His article persuades us, as teachers in positions of authority, to reflect on the implications of our words that we may be unaware of as educators. Many of us are oblivious to our power, as Galinsky argues. His "power amplification affect" is indeed real, and does exist not only in educational spaces but also in other professional relationship dynamics. This idea holds strong implications for how we go about building relationships with students, and showing them that we care about their academic success. The power of educators is not something that is easily dissolved, even in true democratic classrooms. More importantly, our styles of communication convey messages that we may have never intended, however, students' perspective (or that of the "less powerful," according to Galinsky) is what ultimately defines the outcomes of each interaction. Thus, I argue that when examining the power structures that exist and the communication styles that affect their amplification, we must deeply understand who our students are along with their cultural and social norms for communicating with those in an authority role.

Reflecting on how our discourse with students affects relational and educational spaces is a powerful way to acknowledge how care may or may not be present in our interactions with students. Through using a critical discourse analysis to examine our interactions with students, we have the potential to heighten our awareness of hidden power structures and their affects, increase interdisciplinary dialogue, and recognize the discourses that reproduce social power structures within teacher-student relationships (Blommaert, 2005). Blommaert (2005) explains that "when communicating, people 'choose' from a range of options, they 'select' discourse forms deemed appropriate in the particular context, and they consciously 'plan' the sequential moves, either by 'choosing' to 'follow rules' or by 'flouting' these rules" (p. 98). These subconscious authoritative rules that affect how we present ourselves in email communication with students can deeply impact our educational relationships. In education, teachers have control over discourse, both in and out of the classroom. "Who can/may/just say what, to whom, how, in what circumstances and with what effects on the recipients?" (van Dijk, 1996, p. 102).

The objective of critical discourse analysis is to help people increase their consciousness of language and how it affects power, and vice versa (Fairclough, 2001). "Resistance and change are not only possible but continuously happening. But the effectiveness of resistance and the realization of change depend on people developing a critical consciousness of domination and its modalities, rather than just experiencing them" (Fairclough, 2001, p. 3). Thus, if it takes a critical awareness to start to implement change, how can teachers with authoritative power ever begin to change their perspective and analyze their own use of language?

This power of language extends from large political contexts, from the manner of speaking and thus also of thinking that dictatorships and totalitarian orders force upon dominated people, to the small scenes of everyday life, to the arts of seduction of advertising, the sales tricks of telephone marketing, or the menacing undertones at the workplace or in the family. (Weib \& Schwietring, 2014, para. 4)

Language as power surrounds us in every daily interaction with media or people, and especially within discourse between educators and students. If we can begin to analyze and deconstruct the power constructs that are evident in our language use through digital communication with students, then we can move closer to the pedagogy of care and relationships based on democratic spaces, empathy and individual identities.

\subsection{Digital Literacy to Foster Care}

There is no single fixed definition of literacy, but rather, "literacies involve all media forms that combine iconic images, symbol systems, and conventions of presentation" (Lapp, Flood, Heath, \& Langer, 2009, p.3). Every field depends on a distinct array of visual literacies. Perhaps the biggest implication in this claim is that innovative and creative inventions often go beyond the printed text, incorporating new forms of media into what defines participants as being literate in their field. These visual literacies, or symbol systems, accompany both oral and written text, which is crucial for teacher education faculty to accept and explore (Lapp et al., 2009). Learners need to expand their resources and spaces for learning as their abilities to "create, use, and critique information" (Lapp et al., 2009, p. 11) adapt to new symbol systems and new forms of communication. Draper (2010) also acknowledges that the definition of 
literacy has been forced to expand beyond the traditional reading and writing and that some researchers argue that it should include non-print, pictures, and audio content found in a variety of media sources.

Our identities and perspectives shape every situation in which we read, both text and the world. Not only are our forms of communication nuanced but also in how we interpret texts as we read them. Meanings and purposes of texts are influenced by those who read and write them and the context in which the texts are situated (Draper, 2010). Hence, it is imperative to study discourse and technology simultaneously due to how the shifts in technology use in recent years have presented new forms of discourse. Scollon and LeVine (2004) argue the explicit connection between discourse and technology based on the multimodal nature of discourse, and recognize the value in technology for analyzing multiple discourse events across a broader time span, which is what I seek to do in my research. The nature of communication between college instructors and students is often electronic, due to the design of the schedule and the physical span of the college and housing. Because we are not all present in the same building on a regular schedule throughout the week, students and instructors rely heavily on email and other digital forms of communication to get important messages to students and to the whole class. This article seeks to explore that area of discourse and to identify how to use it for richer and more meaningful purposes in education.

\section{My Positionality Toward Care and Technology}

Being entrenched in the scholarly field of education, I believe that how students learn (in regards to their pretexts and their socially-constructed identities) is as important as what students learn. "Education as the practice of freedom affirms healthy self-esteem in students as it promotes their capacity to be aware and live consciously. It teaches them to reflect and act in ways that further selfactualization, rather than conformity to the status quo" (hooks, 2003., p. 72). Sleeter (2005) also advocates for students' cultural assets by "attending to what students in one's own classroom school and classroom already know, the learning process they developed at home, and the language structures they already have" (p. 16). Yet, even today, students are lucky if they have a teacher who recognizes the cultural wealth that they bring to the classroom.

Because of my position (and passion) in teacher education and post-secondary education for diverse populations, as well as in web-enhanced and blended learning models, my research interests gravitate toward how to navigate the educational system and succeed in education. To me, student success can be defined in variety of ways. Academic success as measured by school assessments has only one way. Success can also include growing intellectually, expanding a skillset, maturing emotionally, and building on individual character. When a student has acquired new perspectives, ideas, or skills to take back to their communities, that is success.

This has not always been my position on student success. My White middle-class privilege has allowed access to education to come easy for me, and the use of technology has been at my fingertips in my career, personal life, and educational settings. I would like to explore the challenges that some students (as well as faculty) face in regards to technology access and integration, and how they overcome them, in order to pave the road to success for future students in postsecondary degree programs. Given that many White heterosexual teachers from middle-class backgrounds struggle relating to and teaching children with diverse backgrounds and identities (Delpit, 2006), I am drawn to analyze how our pretexts and ideologies impact the way in which we teach, and the experiences we make available to students. With the flood of technology use in and out of the classroom, I have seen technology have the harmful potential to water down curriculum and pedagogy in that teachers can hide behind the screen avoiding critical analysis of their own pedagogy and meaningful dialogue with students. However, put in the right hands, technology can also be a powerful tool to enhance learning opportunities, and create more space for powerful dialogue. If we can build the capacity to integrate technology use with a culturally-responsive lens and an ethic of care, it can be a tool to enhance learning and student relationships rather than an added challenge for educators.

The focus of this study is on blended and web-enhanced learning, and how higher-education faculty uses technological tools to incorporate care into their relationships with students. As higher education institutions integrate more and more technology in education (at all levels), I became curious about how it influences student-teacher relationships, particularly in the context of diverse learners. More 
specifically, I began to analyze how technology is integrated into the post-secondary classroom, and how students and teachers can use it outside of class to access information, receive feedback from the instructor and peers, and communicate in general. I believe that students learn best when an ethic of care is present in the class environment (whether it be in a classroom or in a web-based setting). As a participant in two online graduate programs, I experienced professors who demonstrated care in their online courses, and those who did not. However, that perception is influenced by my own pretexts and cultural identity, and my individual perception of care. Based on the work of Nel Noddings and the many others who promote meaningful and positive interactions with students (Banks, 2007; Delpit, 2006; Freire, 1970; Gay, 2010; hooks, 1994; Ladson-Billings, 1995, 2009; Valencia, 2010), as well as the many professors who have taught me and demonstrated care in their own teaching), I would define care as the following:

Using an ethic of care with students means seeing them for their individual and cultural identities, responding to their needs as human beings and as learners, and having empathy for their experiences and perspectives. Care means sharing mutually in their academic and emotional wellbeing and, with empathy, helping them grow as learners and as members of their communities. We (teachers) engage in relationships with students to share the learning space, learn from students' unique experiences and perspectives, and to guide them through the learning process while creating a sense of shared power.

Yet, we must ask ourselves, as faculty, if our perception of care is the same as that of students from different sociocultural backgrounds. How can we facilitate a classroom in which our ethic of care will not leave someone feeling neglected?

With the massive shift toward blended, hybrid, and online programs, teachers need to be prepared to offer the same quality of learning experiences and pedagogical practices that they did before the integration of technology, and there is a need for culturally competent teaching practices for diverse learners in online settings. Students can learn if the curriculum and content is meaningful, relevant, personal, and challenging. Technology is a tool to compliment curriculum in ways that can reach those aspects. I am a proponent of technology because I have always used it in my personal life and my career, and it has enhanced my access to information and productivity. I see it as an asset, and others might not share this perception, especially students who may not have access to the Internet or electronic devices off-campus. While this topic might strengthen the educational experience at my college specifically, it can also offer suggestions for improvement to online courses across the country, and support the educational experiences for all students in higher education. Valdes (1996) articulates it eloquently when she explains that "programs that have endeavored to alter or reverse educational outcomes for poor, disadvantaged, or at-risk children have reflected the thinking of theorists who have worked within the deficit-difference paradigm" (p. 29). We cannot assume that because students may not have access to technology that they should not be handed the same 21st-century skills that we provide to other students. My hope is to witness a shift in the paradigm and where we make webenhanced instruction available as an inclusive environment for all students setting them up for success in the higher education classroom.

\section{Problem Statement}

Instructors in higher education are constantly communicating with students regarding their professional growth, personal goals, and academic achievements. Some of this communication takes place in the classroom; however, as more programs shift toward hybrid, technology-enhanced and online models of teaching, much of this communication takes place through the use of digital tools. Students' identities influence how they define care, what they expect of student-professor relationships, and how they interpret online feedback and communication from professors. Professors must consider how students' identities play a role in their communication styles and their definitions of and expectations for care and relationships. Without a defined set of tenets for digital discourse that integrates care, technology can be harmful to students learning experiences rather than a pedagogical and social tool for educators.

\subsection{Research Questions}

After framing multiple perspectives of care within the literature, and exploring how care can be shaped 
by students' diverse cultural backgrounds and identities, I began to analyze my own digital discourse with students throughout the current semester. My intent was to find clarity regarding the following questions:

- What themes of care can be present in digital discourse?

- Through the use of electronic communication with students, what themes are present throughout my own online discourses that meet the definition of care in a higher education classroom?

- How do my responses to post-secondary students differ based on situational aspects, thus varying my demonstration of care and strengthening the student-teacher relationship?

When we (higher education faculty) communicate with students, our message may hold many meanings beyond our intentions or expectations due to the role of the reader as interpreter. Knowing our students' backgrounds, experiences, and identities allows us to create an ethic of care that is individualized and responsive to each learner. I was eager to investigate what those characteristics are when engaging in electronic discourse via email.

\subsection{Methodology}

In assessing how to go about getting the answers to my research questions, I used a qualitative approach in order to measure how people interpret their experiences and perspectives within discourse (Kirby, Greaves, \& Reid, 2006). In this self-analysis, I examined how themes of care emerge through electronic discourse. My analysis is grounded in the conceptual framework of Noddings' (1995, 2005, 2013) ethic of care in education. The social context for the study is discourse used in an introductory teacher preparation course where students are developing basic teaching skills such as lesson planning, writing objectives, and using a variety of effective teaching strategies for diverse students. Because of the rigor of the course and the academic level of the students (primarily sophomores), students seek more guidance than in other courses, hence, the level of communication between myself as the instructor and the students is higher. The discourse sample for this study are all messages sent to students in the selected course within the last academic term (approximately 13 weeks). Having 22 students in the course from diverse backgrounds (male, female, White, Native American), the sample provided ample evidence to code and classify themes related to an ethic of care.

\subsection{Data Analysis}

Sent messages were collected, coded for themes, and analyzed according to their tone, response time, and other characterizing features such as punctuation, empathy, and invitation for students to participate with me in addressing their concerns or questions. These themes can be classified within different approaches to and purposes for correspondence:

1) Time. Emails were collected within one academic semester's time. They were also analyzed for their response rate according to how long it took the instructor to respond to the initial correspondence.

2) Purpose. The purpose of emails is often for clarifying concerns or confusion and asking for support.

3) Participant. The emails selected were sent to participants from one specific course within an academic term, and potentially included 22 students from diverse backgrounds. For the purpose of this study, the recipients of the electronic discourse were not tracked or recorded as the intention was to analyze my own use of digital discourse.

4) Format. As we begin to become more comfortable with digital forms of communication, we tend to use textisms (i.e. txt $\mathrm{msg}$ ) as a social norm throughout other forms of communication such as email or even writing for a broader audience (Plester, Wood, \& Bell, 2008). It is important to keep the tone of emails warm and formal by using proper structure including an opening greeting and a closing that provides comfort, reassurance, or invitation for students to contribute their ideas or preferences.

Themes of care found in the literature included co-constructing knowledge, establishing democratic relationships, responding to student needs through empathy, having the intention to help, and showing respect and an asset-perspective toward students by listening and responding to their different needs. 
These themes guided my analysis of my own discourse toward students throughout the semester and offered tangible characteristics to search for in digital communication.

\subsection{Findings}

Fourteen themes emerged throughout the 110 emails in the sample, and each of the emails was coded for the fourteen themes of care. Those themes included the following: confirmation, timeliness, clarification, gentle/warm tone, formal closure, politeness, academic support, empathy, positivity, gratitude, calming/reassuring tone, options/choice, and invitation (for students to participate with me). The response time for each correspondence was recorded in an effort to see a general trend in timeliness, and also to observe what may affect response time to student concerns. In the 110 emails, response time was always within the same day except in two situations: 1) when the initial emails from students came in late at night, and 2) when the emails from students arrived on the weekend. In those cases, the response time increased to 12-24 hours. Of the other thirteen themes of care observed and coded in the emails, the most prominent characteristic that emerged was invitation for students to participate with me. This was present in 82 of the 110 emails, and as observed in the form of inviting students to stop in to discuss topics further, offering opportunities for them to contest my response, seeking their opinions or thoughts on the topic, and inviting students to request further clarification if needed. The second most prominent theme in the electronic correspondence sample was a warm tone. The challenges in coding this particular theme will be discussed below, and I have included a sample (see figure 1) of how an email was coded for each of the distinct themes. The remainder of the eleven themes found present in the digital discourse are listed here in order of decreasing presence: clarification (55), closure (43), punctuation (43), academic support (36), gratitude (33), politeness (31), reassurance (24), confirmation (23), positivity (23), empathy (18), and choice (17).

\section{Discussion and Analysis}

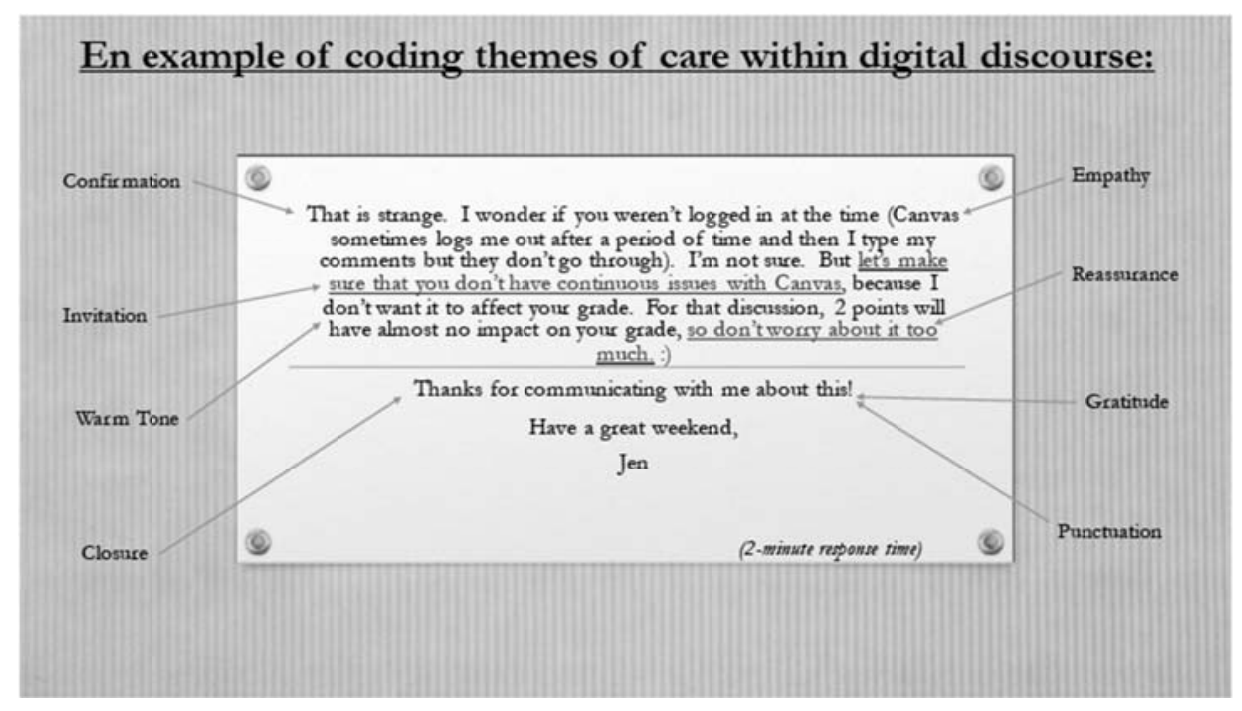

Figure 1. An example of coding themes of care within digital discourse

Of the thirteen themes that emerged from the data, only two of them were presient in the majority of the 110 emails collected and analyzed. Those were invitation and warm tone. In regards to invitation, extending an invitation for students to work with me and giving students an option often go hand-inhand, so the line between those two themes was blurred. For example, on one occasion a student was having difficulties uploading an assignment to Canvas, and my response was: "Why don't you just email me the essay and I'll grade it manually? Or, I am happy to help figure out why Canvas is not letting you upload it. Let me know!" This response provided the choice for the student as to his method of turning in the assignment as well as an invitation for the student to work with me to overcome 
technological glitches and turn in their work. However, inviting students to reach out for more help was a common theme of care throughout the discourse, which aligns with the Noddings' (2005) definition of care, encompassing a positive and sensitive response to students' needs.

Warm tone is a very challenging component to detect in digital discourse. Because I hear my tone of voice in my mind as I read my own written discourse, my assessment of what constitutes a warm and gentle tone gets distorted. Examples of warm tone present in my digital discourse include phrases such as "feel free," "I am happy to," "hope that helps," and "let's make sure." Incorporating a level of sensitivity for readers who may interpret your words in non-intended ways and writing the gentlest message possible were tools that I used in constructing my discourse to students.

\section{Conclusion}

Ultimately, what should the tenets be for using care with students through electronic discourse? Based on existing literature as well as my own discourse analysis, I have constructed five tenets of building care into online communication with students in higher education:

- Construct a mutual relationship around learning through invitation and choice.

- Co-construct meanings and intended learning through shared understanding (Oakes et al., 2012).

- Respond to students' emotional, physical and academic well-being through responding to their needs (Noddings, 2005).

- Show empathy and non-judgment toward students.

- Use critical discourse analysis to evaluate our electronic discourse for empathy, respectfulness, responsiveness, and a sense of support.

In evaluating whether or not I met the ethic of care in my discourse, I believe that (through my own perspective) a strong amount of care was embedded into the electronic discourse for this study. However, interpreting care from only one perspective, or one side of the communication, is challenging and perhaps unattainable. As mentioned earlier, Noddings (2005) believes that care can only build strong teacher-student relationships when both participants (the carer and the cared-for) reciprocate the actions. Through this same lens I would argue that care is present and genuine when it is able to be received by another person. More research needs to be done that includes the students' interpretations of care and how they perceive themes of care from college faculty. Without the voice of students, we can only use our own pretexts to determine how to build positive relationships and construct an ethic of care, which defeats the purpose of care altogether: to respond empathetically and positively to the unique needs of students.

In higher education, electronic forms of communication have become so common that we often do not consider the power they have in terms of building (or hindering) relationships with our students. Because body language and presence are not perceivable in online discourse, we must rely on alternative ways to demonstrate a gentle and supportive tone with students, such as those outlined in the tenets above. By being more aware of our typed messages, we can enhance our relationships with students and create a more caring and democratic learning environment.

\section{References}

1. Banks, J. A. (2007). Educating citizens in a multicultural society (2 edition). New York, NY: Teachers College Press.

2. Blommaert, J. (2005). Discourse: A critical introduction. New York, NY: Cambridge University Press.

3. Comer, J. (1995). Lecture given at Education Service Center, Region IV. Houston, TX.

4. Delpit, L. D. (2006). Other people's children: Cultural conflict in the classroom. New York, NY: The New Press.

5. Draper, R. J. (Ed.). (2010). (Re)imagining content-area literacy instruction. New York, NY: Teachers College Press.

6. Freire, P. (1970). Pedagogy of the oppressed. New York, NY: Continuum. 
7. Galinsky, A. (2015, August 15). When You're in Charge, Your Whisper May Feel Like a Shout. The New York Times. Retrieved from http://www.nytimes.com/2015/08/16/jobs/when-youre-in-charge-your-whisper-may-feellike-a-shout.html

8. Gay, G. (2010). Culturally responsive teaching: Theory, research, and practice. New York, NY: Teachers College Press.

9. Goodman, K. (1996). On Reading (1 edition). Portsmouth, NH: Heinemann.

10.Hooks, bell. (1994). Teaching to transgress: Education as the practice of freedom. New York, NY: Routledge.

11.Hooks, bell. (2003). Teaching community: A pedagogy of hope (1 edition). New York, NY: Routledge.

12.Kirby, S. L., Greaves, L., \& Reid, C. (2006). Experience research social change: Methods beyond the mainstream (2nd ed.). Ontario, Canada: Broadview Press.

13.Ladson-Billings, G. (1995). Toward a theory of culturally relevant pedagogy. American Educational Research Association, 32(3), 465-491. https://doi.org/10.3102/00028312032003465

14.Ladson-Billings, G. (2009). The dreamkeepers: Successful teachers of African American children (2 edition). San Francisco, CA: Jossey-Bass.

15.Lapp, D., Flood, J., Heath, S., \& Langer, J. (2009). The communicative, visual and performative arts: Core components of literacy education. In J. V. Hoffman \& Y. Goodman (Eds.), Changing Literacies for Changing Times: An Historical Perspective on the Future of Reading Research, Public Policy, and Classroom Practices (pp. 3-16). New York.

16.Noddings, N. (1995). Teaching themes of care. The Phi Delta Kappan, (9), 675.

17.Noddings, N. (2005). The Challenge to care in schools: An alternative approach to education. Advances in contemporary educational thought, Volume 8. (2nd ed.). New York, NY: Teachers College Press. Retrieved from http://eric.ed.gov/?id=ED377590

18.Noddings, N. (2013). Education and democracy in the 21st century. New York, NY: Teachers College Press.

19.Noddings, N. (2014). High morale in a good cause. Educational Leadership, 71(5), 14-18.

20.Oakes, J., Anderson, L., Lipton, M., \& Stillman, J. (2012). Teaching to change the world. Saint Paul, MN: Paradigm Pubishers.

21.Palmer, P. J. (1997). Teaching and learning in community. About Campus, 2(5), 4-13.

22.Pierson, R. (2013). Every kid needs a champion. TED. Retrieved from https://www.ted.com/talks/rita_pierson_every_kid_needs_a_champion.

23.Plester, B., Wood, C., \& Bell, V. (2008). Txt msn n school literacy: does texting and knowledge of text abbreviations adversely affect children's literacy attainment? Literacy, 42(3), 137-144.

24.Scollon, R., \& LeVine, P. (2004). Multimodal discourse analysis as the confluence of discourse and technology. In Scollon, Ron \& P. LeVine (Eds.), Discourse and technology: Multimodal discourse analysis (pp. 1-6). Washington, D.C: Georgetown University Press.

25.Sleeter, C. E. (2005). Un-standardizing curriculum: Multicultural teaching in the standards-based classroom. New York, NY: Teachers College Press.

26.Valdes, G. (1996). Con respeto: Bridging the distances between culturally diverse families and schools: An ethnographic portrait. New York, NY: Teachers College Press.

27.Valencia, R. R. (2010). Dismantling contemporary deficit thinking: Educational thought and practice (1 edition). New York, NY: Routledge.

28.van Dijk, T. A. (1996). Discourse, power and access. In C. R. Caldas-Coulthard \& M. Coulthard (Eds.), Texts and practices: Readings in critical discourse analysis. New York, NY: Routledge. Retrieved from http://www.discourses.org/OldArticles/Discourse,\%20power\%20and\%20access.pdf

29.Weib, J., \& Schwietring, T. (2014). The power of Language: A philosophical-sociological reflection. Retrieved from http://www.goethe.de/lhr/prj/mac/msp/en1253450.htm

30.Wood, G., \& Lemley, C. (2015). Mapping cultural boundaries in schools and communities: Redefining spaces through organizing. Democracy and Education, 23(1). Retrieved from http://democracyeducationjournal.org/ home/vol23/iss1/3 